\title{
Revista de Filosofía
}

ISSN: 0034-8244

http://dx.doi.org/10.5209/RESF.55446

\section{La memoria de los vencidos: historia y justicia en el pensamiento de Simone Weil ${ }^{1}$}

Cristina Basili

Recibido: 22 de marzo de 2015 / Aceptado: 19 de mayo de 2015

Resumen. La instauración de un vínculo entre historia y poder es uno de los aspectos más interesantes del pensamiento político de la filósofa francesa Simone Weil (1909-1943). Durante la primera mitad del siglo XX, Weil desarrolla unas reflexiones en torno al concepto de historia, desde la perspectiva de los vencidos, que aproximan su especulación a la de su contemporáneo Walter Benjamin (1892-1940). La comparación con Benjamin permite acercar el pensamiento weiliano a las recientes teorías de la justicia anamnética y, más en general, a la exigencia actual de incorporar en el discurso político el punto de vista de las víctimas.

Palabras claves: historia; poder; justicia; víctimas; vencidos; Roma; Grecia; Weil; Benjamin.

\section{[en] The Memory of the Vanquished. History and Justice in Simone Weil's Thought}

\begin{abstract}
The restoration of a link between history and power is one of the most interesting aspects of Simone Weil's political thought. During the first half of the 20th century, Weil developed reflections on the concept of history from the perspective of the vanquished. In this way, her thought comes close to that of her contemporary Walter Benjamin. Reading Weil together with Benjamin helps to point out a dialogue between Weil's work and recent theories of anamnetic justice, as well as, more generally, the current move to incorporate the victims' point of view into political discourse.
\end{abstract}

Keywords: history; power; justice; victims; vanquished; Rome; Greece; Weil; Benjamin.

Sumario. 1. Introducción; 2. En torno a una justicia anamnética; 3. Contar otra historia; 4. La lectura del pasado; 5. Conclusiones; 6 . Referencias bibliográficas.

Cómo citar: Basili, C. (2017): "La memoria de los vencidos: historia y justicia en el pensamiento de Simone Weil”, en Revista de Filosofía 42 (1), 41-57.

\footnotetext{
1 Este artículo se inscribe en el marco del Proyecto de Investigación "Ley y Estado en la teoría política clásica: justicia y ciudadanía en el pensamiento político de Platón y Aristóteles” (FFI2010-16506), financiado por el Ministerio de Economía y Competitividad.

2 Universidad Carlos III de Madrid cbasili@hum.uc3m.es
} 


\section{Introducción}

En tiempos recientes, la reacción crítica frente al escándalo de la Segunda Guerra Mundial y a la violencia sistemática de los regímenes dictatoriales que, en los años cincuenta del siglo XX, se había constituido como reflexión sobre la categoría de totalitarismo ${ }^{3}$, ha venido asumiendo la forma, más conforme a la sensibilidad democrática contemporánea, de un pensamiento en torno al estatuto de las víctimas, al valor epistémico de la memoria y a los márgenes de la justicia ${ }^{4}$. La tarea teórica de pensar el acontecimiento de lo impensable se ha desarrollado, en un primer momento, como estudio del recorrido de la razón occidental -bajo la forma de un cuestionamiento de las raíces de nuestra civilización- pero el esfuerzo epistémico y hermenéutico de entender los fenómenos políticos del siglo pasado y del presente ha dejado paso progresivamente a un enfoque distinto de la cuestión ${ }^{5}$. Un conocimiento más detenido de los hechos, junto a una extensa literatura, proporcionada, en la mayoría de los casos, por el testimonio de los supervivientes, ha permitido que a las narraciones filosóficas sucediera una aproximación más cercana a los rostros concretos de quien ha padecido la violencia. A partir de las primeras reflexiones sobre el horror del Holocausto -evento clave en torno al cual converge la reflexión relativa a los otros innumerables exterminios que han marcado la historia del siglo $\mathrm{XX}$ - se ha desarrollado una perspectiva filosófica que asimila el punto de vista de las víctimas como centro a partir del cual declinar la relación entre violencia y política. El discurso normativo moderno que intenta instaurar un nexo entre política y guerra con el fin de utilizar la violencia como herramienta privilegiada del orden social, dentro y fuera de los confines de los Estados, parece inadecuado para entender los acontecimientos contemporáneos. Uno de los fenómenos que más ha contribuido a la hora de reactivar y agudizar este tipo de pensamiento ha sido, sin duda, el terrorismo. En tanto consecuencia del marco de indistinción creado por el conjunto de procesos políticos, culturales y económicos de la globalización, ha vuelto a reclamar con fuerza dentro de la filosofía occidental una reflexión en torno a la herencia política de la modernidad y de sus degeneraciones ${ }^{6}$. La inagotable sucesión de matanzas que configuran la historia de los últimos dos siglos excede la lógica utilitarista de los medios y de los fines, dibujando un escenario ininteligible para las categorías políticas modernas. Una forma de abordar la cuestión pasa por activar una dinámica diferente entre el punto de vista de quien ejerce y de quien padece la violencia, asumiendo la última perspectiva como enfoque teórico capaz de proporcionar una respuesta política al hecho de la violencia ${ }^{7}$. La politización del punto de vista de la víctima es el resultado de un discurso incapaz de sostener la productividad política de los conflictos, frente a la caída de las ideologías tradicionales que los sustentaban. Sin embargo, este enfoque puede proporcionar un descentramiento respecto a las

3 Para una reconstrucción teórica del debate en torno a la noción de totalitarismo véase: González Calleya (2012, pp. 9-46) y Forti (2001).

$4 \quad$ Ejemplos de este tipo de literatura son los siguientes trabajos: Ferry (2001); Margalit (2002); Mardones/Mate (2003); Ricoeur (1998).

5 "Tras la experiencia del Holocausto, la memoria consiste en reconocer que lo impensable ha tenido lugar y entonces se convierte en algo que da de pensar", así se expresa Reyes Mate, en Ares (2011, p. 36).

Sobre la lógica especular que domina la dialéctica entre terrorismo y guerra al terrorismo, cfr. Galli (2007).

Véase a este respecto la distinción proporcionada por Adriana Cavarero entre el punto de vista del "guerrero" y el de la "víctima inerme" en Cavarero (2007a) y en Cavarero (2007b). 
lógicas modernas de constitución y mantenimiento del poder, sólo a cambio de que la victimización no sea la forma actual bajo la que se presentan viejos mecanismos de exclusión. El movimiento de universalización subyacente a la categoría de víctima puede ser políticamente productivo si preludia una tarea crítica que reconozca las declinaciones históricas de las prácticas de ejercicio del poder, revitalizando desde dentro el debate en torno a la legitimidad democrática ${ }^{8}$. La conmemoración de las víctimas no se puede transformar en el móvil de un desencadenamiento vengativo y sin fin de la violencia, sino en una ocasión para reconocer a todas las víctimas como tales porque son inermes frente a una insostenible ecuación entre política y potencia.

En este marco de discusión cabe encuadrar la reflexión de la filósofa francesa Simone Weil (1909-1943). Su pensamiento, a partir de los años treinta, se ha dedicado a vaciar las pretensiones de las ideologías dominantes, oponiendo una crítica radical de las dinámicas de constitución del poder a la inconsistencia de los discursos que legitiman el recurso a la violencia. Su reflexión se coloca desde el punto de vista de las víctimas para denunciar, en un primer momento, las aporías de una justificación utilitarista de la violencia - de un medio que excede todos los fines- y, en segundo lugar, para desmantelar la idolatría del poder que subyace a la constitución política de Occidente. Las reflexiones de la pensadora en torno a la Guerra de España -en la cual Weil participa en 1936, acudiendo, al lado de los republicanos, al frente de Barcelona- llevan a cabo un trabajo, empezado con la crítica al marxismo, que se apoya en el potencial filosóficamente subversivo de la mirada de las víctimas para colapsar la estrategia moderna de legitimización política de los conflictos ${ }^{9}$. La reducción de la guerra a violencia, producida por la adopción de la perspectiva de la víctima, persigue el objetivo teórico de disolver la trivialidad semántica de la oposición entre facciones opuestas: entre "nosotros" y "los demás", entre "el amigo" y "el enemigo". El enfoque en los sufrimientos de la población inocente e inerme opone a cada intento de racionalización el carácter nihilista de las masacres. Este aspecto destaca en el análisis desarrollado por la pensadora en una conmovedora carta al escritor Georges Bernanos, supuestamente su "adversario" político, con el cual Weil comparte el mismo sentimiento de rechazo al uso instrumental de la violencia:

Cuando las autoridades temporales y espirituales han puesto una categoría de seres humanos fuera de aquellos cuya vida tiene un precio, no hay nada más natural para el hombre que matar. Cuando se sabe que es posible matar sin arriesgarse a un castigo ni reprobación, se mata; o al menos se rodea de sonrisas alentadoras a aquellos que matan ${ }^{10}$.

El descentramiento de la perspectiva respecto a la tradición de un realismo político que se conforma con el intento de normalizar el conflicto dentro de la forma políticamente productiva de la guerra revela una excedencia de la violencia en relación al poder que corrompe el discurso normativo moderno: la artificiosa separación, dentro de lo humano, entre vidas que tienen valor y otras que no lo tienen no supera la prueba de la mirada de las víctimas y preludia, en el pensamiento de Weil, una naturalización del poder como fuerza que posibilita un trabajo crítico de

\footnotetext{
8 Véase las reflexiones de la filósofa estadounidense Judith Butler a la hora de analizar críticamente el debate público en la política norteamericana después del ataque del 11/9 en Butler (2006).

$9 \quad$ Cfr. Guaraldo (2009), pp. 73-110.

10 Weil (2007), p. 525.
} 
revisión de toda una tradición filosófico-política. Si se acerca el pensamiento weiliano a una de las perspectivas más interesantes a este respecto en el contexto actual -la de denominada justicia anamnética-, se puede destacar uno de los ejes que, junto con el rechazo de la exclusividad del estatuto de víctima, sostiene el discurso de una responsabilidad ética ante los crímenes políticos: el vínculo entre historia y poder.

\section{En torno a una justicia anamnética}

La teoría de la justicia anamnética se propone dilatar el marco usual de la justicia legalista, tal como es concebida en los Estados de derecho, centrándose en la importancia del punto de vista de las víctimas y valorando la memoria como categoría política clave para asumir una responsabilidad social y colectiva frente a la a los crímenes. Este discurso, surgido a partir de la reflexión sobre el Holocausto, se basa en los pensadores de origen judío que, a mediados del siglo pasado, se dedicaron a fundamentar un pensamiento ético que asumiera el valor cognitivo y epistémico de la tragedia representada por la Segunda Guerra Mundial: Horkheimer, Adorno, Brecht, Lévinas, Rosenzweig y otros ${ }^{11}$. Para los teóricos de la justicia anamnética, Auschwitz representa el evento clave que desencadena el discurso sobre poder y violencia, confiriéndole una radicalidad que es condición sine qua non para repensar las condiciones actuales de la vida pública ${ }^{12}$. Una argumentación de este tipo implica algunas dificultades: por ejemplo, la idea de normalizar en los procedimientos jurídicos una instancia de orden moral puede llevar al uso de un lenguaje teológicopolítico como el de la venganza, las víctimas inocentes y la culpa - que es peligroso reactivar dentro del debate público ${ }^{13}$.

Sin embargo, estos apuntes críticos no quitan importancia teórica a un marco de discusión que evidencie la correlación intrínseca entre historia y poder -olvido e injusticia- al fin de responder a una nueva sensibilidad moral encabezada por el reconocimiento de la concreción ineludible de quien ha padecido violencia. La tarea que se ha de cumplir, desde esta perspectiva, es la de plantear una visión de la historia que se haga cargo de la presencia de dos visiones de la realidad: la de los vencidos y la de los vencedores, a fin de acudir a un tipo de universalidad que reconozca el derecho de cada uno de los hombres, también los muertos y los fracasados, a la recuperación de lo perdido ${ }^{14}$ :

Pensar desde el dolor de las víctimas produce una verdadera revolución ética. Surge una ética que no tolera la presunta imparcialidad ni el formalismo de las éticas comunicativas ni del liberalismo rawlsiano. Se sitúa en la socialidad, la relación con el otro, la víctima, que interpela desde su mirada y sienta ya la responsabilidad como primer paso ético

11 Para el tratamiento de estos autores en relación a la idea de justicia anamnética, véase: Zamora/ Mate (2011).

12 Argumenta Mate (2011, pp. 5-6) que el análisis filosófico de Auschwitz "nos ha aproximado a un concepto de justicia que se interroga por los derechos negados en el pasado, por la vigencia del daño que sufrieron las víctimas inocentes, por los vínculos entre la injusticia presente y pasada. A partir de este vínculo se hace patente que hacer justicia no consiste sólo en castigar al culpable, sino también en adoptar la perspectiva de las víctimas. Esto supone, en primer lugar, no suplantar la realidad por un marco abstracto de reglas pactadas según criterios de universalidad formal. Los oprimidos y aquellos que sufren la injusticia han experimentado con desencarnada evidencia que su singularidad nunca encuentra cobijo en esa universalidad".

13 Cfr. Valladolid Bueno (2011), pp. 217-248 y Cerutti (2011), pp. 243-266.

14 Cfr. Mate (2003), pp. 100-125. 
que me induce a cargar con su suerte. En la respuesta a la interpelación del otro nace la libertad y no antes. El sujeto ético se constituye desde esta heteronomía que señala la dependencia de la relación interpersonal y el rostro interpelante del otro ${ }^{15}$.

Proporcionar una instancia ética de este tipo implica una reflexión crítica que asuma la herencia y la responsabilidad del pasado y la plante dentro del presente para activar una dinámica constructiva desde la que la historia ya no pueda ser un recorrido cerrado, sino un vector de la construcción de un orden social y político más justo. La primera cuestión que se propone es entonces la de fundamentar teóricamente una concepción de la historia consciente del potencial utópico presente en una lectura del pasado que se ubique en la perspectiva de las víctimas: ésta consentiría develar el engaño de una neutralidad pensada como neutralización y normalización, mientras que, precisamente por su intento innovador, procuraría evadir el riesgo reaccionario siempre latente en cualquier idealización de lo que ha sido. La segunda idea clave en este análisis es la definición del estatuto de la víctima: lo que interesa no es una mera ostentación conmemorativa, sino la crítica a los fundamentos de la lógica que causó la injusticia. El significado de ser víctima consiste, según Reyes Mate, en "ser instrumentalizado por un fin; en ser violentado al servicio de una lógica política que avanza sobre sufrimientos de inocentes"16.

\section{Contar otra historia}

La posibilidad de acercar el pensamiento de Simone Weil a este marco de reflexión se hace más evidente si se piensa que el análisis de Walter Benjamin en el texto Sobre el concepto de historia ${ }^{17}$ desempeña un papel central en la elaboración del discurso filosófico en torno a la justicia anamnética ${ }^{18}$. La versión del materialismo histórico propuesta por Benjamin se articula, a través de la crítica a la noción de progreso, como una desestructuración de la tradición de los vencedores que permita emerger a la tradición de los vencidos del fondo oscuro en el que se ha quedado a largo de la historia. Benjamin concibe la revolución como una fractura utópica que interrumpe la concepción cuantitativa y acumulativa del tiempo, a favor de la inmediatez de la redención: una movilización creativa capaz de deconstruir las jerarquías de poder e instaurar un orden fundado sobre la justicia.

Sin embargo, la justicia de la que habla Benjamin es una justicia que, como el filósofo apunta en el texto Crítica de la violencia ${ }^{19}$, se define por su oposición al derecho y a la lógica estatal. La violencia que Benjamin reconoce como fondo ineludible de la organización política moderna es la misma violencia que se encuentra según él en la base de la historia. Como el de Weil, el pensamiento del filósofo alemán, siguiendo la tradición del socialismo francés ${ }^{20}$, pretende alejar el concepto de política

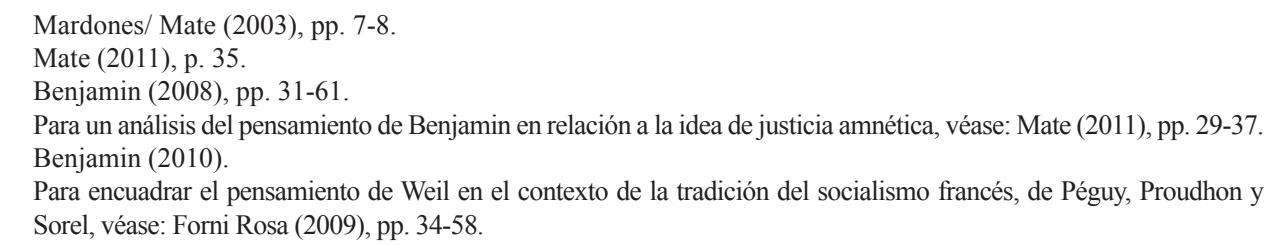


de la noción de interés y situar en lo metafísico su potencial no instrumental ${ }^{21}$. A la violencia del derecho y del Estado Benjamin contrapone una Justicia que entra en la esfera humana sin mediaciones y que anima una dialéctica negativa fundada en el reconocimiento de la interacción entre civilización y barbarie: "no hay documento de cultura que no sea a la vez documento de barbarie"22. Benjamin contempla un tiempo constantemente abierto que no admite la individualización de un movimiento progresivo de la historia, según una postura en consonancia con las reflexiones que Weil desarrolla en ese mismo periodo:

Hoy no podemos ya tener la misma confianza ingenua en el progreso que tuvieron nuestros padres y nuestros abuelos; pero buscamos todas las causas para la barbarie que llena de sangre el mundo fuera del medio en que vivimos, en grupos humanos que nos son extraños o que afirmamos que lo son. Querría proponer que consideráramos la barbarie como una característica permanente y universal de la naturaleza humana, que se desarrolla más o menos según las circunstancias le son más o menos favorables ${ }^{23}$.

Benjamin, como Weil, partiendo de una crítica radical de la política como violencia, elabora, a través de la rememoración de las víctimas del pasado, una concepción activa de la historia en la que la tradición olvidada de los oprimidos es aquel vinculo que permite mantener abierto el proceso de construcción del presente. Entendida como un encuentro secreto entre las generaciones pasadas y las futuras, la política, para el filósofo alemán, ha de incorporar en su interior fragmentos de tiempo mesiánico que interrumpan el continuum de la historia ${ }^{24}$

La tradición de los oprimidos nos enseña que el "estado de excepción" en el que ahora vivimos es en verdad la regla. El concepto de historia al que lleguemos debe resultar coherente con ello. Promover el verdadero estado de excepción se nos presentará como tarea nuestra, lo que mejorará nuestra posición en la lucha contra el fascismo. La oportunidad que éste tiene está, en parte no insignificante, en que sus adversarios lo enfrenten en nombre del progreso como norma histórica. El asombro ante el hecho de que las cosas que vivimos sean "aún" posibles en el siglo veinte no tiene nada de filosófico. No está en el comienzo de ningún conocimiento, a no ser el de que la idea de la historia de la cual proviene ya no puede sostenerse ${ }^{25}$.

A partir de estas reflexiones de Benjamin, los teóricos de la justica anamnética instauran un vínculo entre memoria y justicia -e injusticia y olvido-que apunta hacia una crítica de la concepción liberal de la justicia utilizando el momento del recuerdo de las víctimas como dispositivo para desmontar la lógica de violencia operante en la historia. Se trata de una forma de interpretar el pensamiento de Benjamin que, en parte, evade la cuestión del contexto histórico y de la tradición filosófica a partir de la cual se mueve el discurso del filósofo. Para Benjamin la tradición de los vencidos sigue enlazada a la idea marxiana del proletariado como sujeto histórico; no obstante,

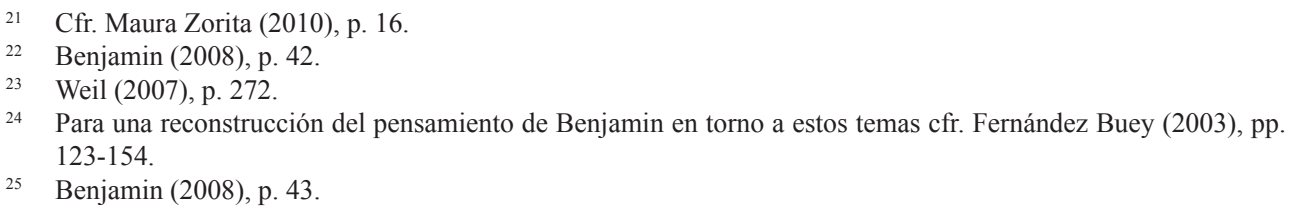


la crítica al historicismo tiene como fin la desestructuración de una concepción lineal y progresiva del tiempo. Para Benjamin, se trata de rescatar la tradición de las masas explotadas que, solamente gracias una yuxtaposición hermenéutica, pueden ser identificadas con las víctimas que pueblan el imaginario político contemporáneo. Este pasaje hacia una naturalización y universalización del estatuto de víctima será, en cambio, una característica del pensamiento de Weil. Sin embargo, las reflexiones de Benjamin apuntan en dirección de una crítica de la violencia y del progreso encaminada a terminar con una historia que se identifica con la historia del poder y de los dominadores, para sugerir la idea de que un orden político más justo sólo es posible a partir de una reactivación inmediata de la tradición de los oprimidos. Esta concepción considera cada instante y cada momento histórico potencialmente como revolucionario: "no hay un instante que no traiga consigo su oportunidad revolucionaria -sólo que ésta tiene que ser definida en su singularidad específica, esto es, como la oportunidad de una solución completamente nueva ante una tarea completamente nueva"26.

La crítica de la noción de derecho, la crítica al progreso y a una civilización fundada sobre la violencia, el olvido de los oprimidos, junto con una concepción de la justicia que se convierte en motor político de una historia abierta, no son sólo los rasgos que señalan a Benjamin como referente teórico de la construcción de un pensamiento en torno a la necesidad de una anamnesis compartida y de una ética ante las víctimas, sino que son también los temas que sustentan una posible comparación entre su pensamiento y la elaboración filosófica de Simone Weil. Ya muchos intérpretes han señalado que la filósofa francesa desarrolla, más o menos en los mismos años, reflexiones muy parecidas sobre la crítica al marxismo, la crítica al progreso, la violencia inherente al derecho, la importancia del pasado y la necesidad de una elaboración política que se posicione en el punto de vista de las víctimas ${ }^{27}$. Como Benjamin, Weil llega a su noción de la justicia a partir de una concepción de la historia que se desarrolla gracias a un diálogo intenso e ininterrumpido con la tradición marxista, de la cual rechaza como ilusoria la idea de un camino de la humanidad y de los medios de producción hacia un progreso indefinido mientras que no sólo retiene el método materialista de análisis de los fenómenos sociales, sino también la perspectiva con la cual se ha de mirar la realidad: la de los oprimidos, la de los explotados y, finalmente, la de todas las víctimas sacrificadas a las dinámicas del poder y de la fuerza ${ }^{28}$. Ambos pensadores abandonan la posibilidad de entender dialécticamente los acontecimientos del mundo en el que viven -lacerado por la guerra, los totalitarismos y las potencias técnicas y económicas despertadas por el capitalismo avanzado- y la contradicción, la irracionalidad del mundo se proyecta contra y dentro del pensamiento, catapultando la libertad y la justicia fuera de la historia y de la política, dominios de la fuerza y de la violencia. Esta consonancia

26 Benjamin (2008), p. 56.

27 Cfr. Fernández Buey (2003), pp. 123-154; Canciani (2009), pp. 43-60; Bea (2009), pp. 75-90; Carillo (2009), pp. 91-109.

28 Cfr. Forni Rosa (2009), pp.13-14. El planteamiento de la cuestión política a partir de la condición de exclusión social es una constante del pensamiento de Simone Weil, desde las primeras reflexiones sobre la condición obrera; también el acercamiento al cristianismo es posible en cuanto la filósofa lo interpreta como la "religión de los esclavos". El proletariado ya no es marxianamente "sujeto histórico" porque, a causa de la experiencia de la Unión Soviética, Weil desconfía en las posibilidades de una revolución comunista, pero el interés por los trabajadores sigue siendo central a lo largo de toda su reflexión, orientándose, en los últimos años, hacia una mística del trabajo. 
entre los dos pensadores ha sido destacada, entre otros, por Emilia Bea que también ha hecho explícita la afinidad existente entre la concepción de la justicia weiliana y la propuesta de un horizonte anamnético:

En oposición radical a la noción desarraigante de progreso, para S. Weil la necesidad de recuperar el pasado se funda en los mismos presupuestos de lo que, partiendo del pensamiento de W. Benjamin o J.-B. Metz, ha sido definida como "solidaridad anamnética", es decir, se basa en una solidaridad universal que recuerda y hace suya la causa de los vencidos y olvidados de la historia. Frente a una idea de revolución que Weil califica de "opio del pueblo", la única revolución que para ella merece este nombre es la que proclama que "lo nuevo" ya ha comenzado en cada compromiso por la justicia, en la voz de quienes a lo largo de los siglos han experimentado la opresión y han gastado su vida en la lucha no demasiado eficaz, pero en ningún caso inútil, por conseguir mejores condiciones técnicas, económicas y sociales para todos. La revolución, lejos de exigir una ruptura con el pasado, exige que el pasado continúe abierto, que la "memoria dolorosa" ilustre aquello con lo que el hombre nunca podrá conformarse ${ }^{29}$.

Sin embargo, la distancia entre los dos autores se produce en la manera en la que se entiende la recuperación de elementos éticos y espirituales como posibilidad de reanudar un discurso político que se halle en una dimensión lógica (e histórica) distinta de la de la tradición moderna. Para profundizar en este discurso haría falta un estudio detallado de la controvertida interpretación de la tradición judía por parte de Weil, quien rechaza - coherentemente con su repudio de la idea de una finalidad de la historia- la idea de pueblo elegido como una declinación teológicopolítica equivalente a la noción secularizada de progreso. La cuestión del presunto antijudaísmo de Simone Weil ha interesado mucho a sus intérpretes y, deparándole ásperas críticas, no ha parado de suscitar inquietudes ${ }^{30}$ : los análisis han subrayado el escaso valor de sus observaciones sobre el texto bíblico, sus prejuicios e incluso su mala $\mathrm{fe}^{31}$. Sin embargo, no han faltado las tentativas de enlazar el pensamiento weiliano con el pensamiento judío post-Auschwitz ${ }^{32}$. Son muchos los elementos que permiten acercar las dos posiciones: la búsqueda de una religiosidad auténtica, las reflexiones en torno a la desdicha y al silencio de Dios, la responsabilidad mutua entre los hombres, el tema de la caridad, la escritura como forma de resistencia. Estos argumentos vuelven a aproximar a Weil al marco teórico tomado en consideración y a reclamar una apreciación más detenida de las implicaciones de su interpretación de la historia.

$29 \quad$ Bea (1992), pp. 284-285.

30 Recientemente, ha sido traducido al castellano: En casa de los Weil. André y Simone, la primera biografía de Simone Weil escrita por alguien de su familia. La autora es su sobrina Sylvie, escritora y estudiosa de judaísmo, que, interrogándose sobre el enigma de la vida de su tía, vuelve a plantear la cuestión del judaísmo en el pensamiento weiliano, de una parte, destacando los elementos hebraicos de su reflexión, de otra, problematizando el rechazo de su origen judío. Véase: Weil (2011).

31 Se indican algunos de los textos más relevantes: Nevin (1991); Giniewski (1978); Lévinas (1952).

32 Cfr. Bea (2009), pp. 75-90. Otra tentativa de enlazar Weil al pensamiento sobre el Holocausto, a partir de una perspectiva de género, se encuentra en Feldhay Brenner (2005). 


\section{La lectura del pasado}

El pensamiento de Simone Weil evoluciona a lo largo de una década, desde los primeros años treinta hasta los primeros años cuarenta del siglo XX, pero la confutación de la noción de progreso permanece como una constante a partir de las primeras reflexiones que se confrontan con el marxismo. Como Benjamin, Weil desconfía de la posibilidad de que se pueda llevar a cabo la emancipación social a través de un cambio espontáneo e inevitable de las condiciones económicas y materiales del capitalismo, pero al contrario que éste, para el cual la noción de revolución sigue teniendo sentido aunque sólo como esperanza mesiánica -"la sociedad sin clases no es la meta final del progreso en la historia, sino su interrupción, tantas veces fallida y por fin llevada a efecto" 33 - llega a decretar imposible la revolución como factor de emancipación social. Para Weil todas las revoluciones a lo largo de la historia han fracasado, consiguiendo en la mejor de las hipótesis sustituir un régimen opresivo por otro:

Lo que la historia nos presenta son lentas transformaciones de regímenes en las que los acontecimientos sangrientos, que bautizamos como revoluciones, juegan un papel muy secundario y pueden, incluso, estar ausentes; éste es el caso cuando una clase social, que dominaba en nombre de las antiguas relaciones de fuerza, llega a conservar una parte del poder en nombre de las nuevas relaciones: la historia de Inglaterra proporciona un ejemplo. Pero, por muchas formas que tomen las transformaciones sociales, cuando se intenta poner al desnudo su mecanismo, sólo se percibe un sombrío juego de fuerzas ciegas que se unen o se enfrentan, que progresan o decaen, sin dejar jamás de triturar a los desdichados humanos ${ }^{34}$.

Lo que se llama revolución, aunque tenga la capacidad de instaurar un nuevo orden social, no puede suprimir las condiciones de la opresión porque éstas tienen su fundamentación en la división del trabajo que sustenta la complejidad de las asociaciones humanas. La evolución de las sociedades implica una gestión vertical y jerárquica del poder que penaliza siempre a la mayoría a favor de una minoría de privilegiados. Weil, de este modo, utiliza el método materialista de análisis de los fenómenos sociales para llegar a una naturalización de la noción de fuerza que es interpretada, de una parte, como necesidad, de otra, como lucha por el poder, un mecanismo, falsamente utilitarista, que da cuenta del "absurdo esencial que se da en el corazón mismo de la vida social" ${ }^{\prime 35}$ :

El poder, por definición, sólo constituye un medio; mejor dicho, poseer un poder consiste, simplemente, en poseer los medios de acción que sobrepasan la restringida fuerza de la que un individuo dispone por sí mismo. Pero la búsqueda del poder, por su esencial incapacidad de apropiarse de su objeto, excluye cualquier consideración de fines, llegando, en una inevitable inversión, a ocupar el lugar de todos los fines. Esta inversión de la relación entre el medio y el fin es la locura fundamental que da razón de todo lo que hay de insensato y sangriento a lo largo de la historia. La historia humana es la historia de

\footnotetext{
Benjamin (2008), pp. 69-70.

Weil (1995), pp. 93.

Ibíd., p. 85.
} 
la esclavitud que hace de los hombres, tanto de los opresores como de los oprimidos, el simple juguete de los instrumentos de dominación que ellos mismos han fabricado; rebaja así a la humanidad viva a ser un objeto de la materia inerte ${ }^{36}$.

La contradicción, sin posibilidad de conciliación, se instaura entonces para Weil como ley de los acontecimientos humanos; según apunta Esposito, para Weil "la ideología del progreso se revoca aquí no menos que aquella otra, complementaria, de la decadencia, a favor de una valoración de la fuerza como una constante universal, invariable, a no ser en la medida, de la naturaleza humana" ${ }^{37}$. La historia, en este contexto, es el campo de una dialéctica que no tiene resolución posible: que no tiene composición mundana positiva ${ }^{38}$. Esta consideración del carácter contradictorio o irracional de la historia ${ }^{39}$ se agrava en el pensamiento weiliano con los acontecimientos de esos años en los que se desarrolla su producción filosófica. El clima de espera trágica que precede el estallido de la Segunda Guerra Mundial y el ascenso de los totalitarismos inducen a la filósofa a asumir la tarea de pensar la categoría de fuerza como eje de una reflexión que no se quiere refugiar en el engaño de la ilusión para permanecer fiel al orden de la realidad ${ }^{40}$. Weil empieza a desarrollar la idea de que la historia puede ser leída, en cuanto reino eterno de la fuerza, a la sombra del presente ${ }^{41}$. Contemporáneamente, el surgimiento de un interés de naturaleza religiosa y espiritual hace que dentro de aquella misma historia Weil comience a reconocer los gérmenes de una historia distinta que brilla con luz propia. De esta manera, la reflexión política empieza a evolucionar, sin perderse, gracias a los aportes de la meditación sobre cuestiones religiosas y espirituales. La afición política por las masas explotadas, por los obreros, por los campesinos, por los pobres y los desdichados converge entonces, según un movimiento de universalización, con la compasión por todos aquellos que, a lo largo de la historia, han sido humillados por el ejercicio del poder, víctimas de la violencia y de la injusticia: que han sido vencidos y han desaparecido por la brutalidad de la fuerza. La filósofa comienza a dedicarse a un estudio del pasado entendido como fuente de un conocimiento natural y sobrenatural que persigue el fin político de pensar las relaciones sociales en un horizonte que supere la derrota hermenéutica de las categorías políticas modernas. La equiparación impolítica entre política y poder y la asimilación del poder a un ejercicio irracional de la fuerza que desencadena un orden fundado sobre la violencia no dejan otro margen a la reflexión que el de un salto analógico en la historia ${ }^{42}$. La lectura del pasado es para Weil, de una parte, un recurso para llevar a cabo una crítica de las raíces de la tradición política occidental -en cuyo fondo encuentra aquel vínculo entre derecho y violencia analizado también por Benjamin ${ }^{43}$, de otra, una fuente de inspiración para pensar la convivencia social fuera del marco personalista de la apropiación y la reivindicación. El precio que Weil paga para

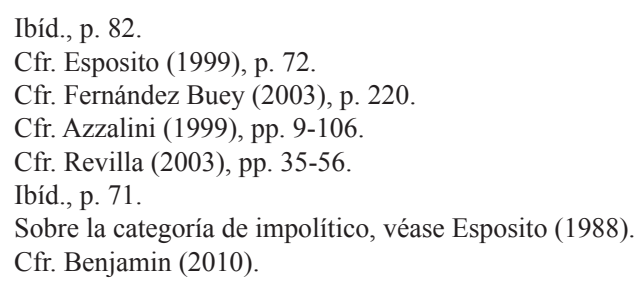


llegar a la elaboración de una política de las obligaciones y del enracinement ${ }^{44}$ pasa por una escasa consideración hacia la declinaciones dinámicas e históricas del poder, a favor de una visión dualística que Emmanuelle Gabellieri ha definido como una dialéctica entre la "historia de la gracia" y la "historia de la fuerza" ${ }^{45}$. De otra forma, se podría hablar de una lectura del pasado que contempla, de una parte, la historia -los documentos dejados por los vencedores, la elegía de la falsa grandeza, los monumentos al culto de la fuerza-, de otra, la memoria: la fragilidad de las huellas de los vencidos, el testimonio de las víctimas. Los escritos que Weil compone meditando sobre el hitlerismo representan un ejemplo de este tipo de argumentación y proporcionan una clave para valorar el conjunto de su reflexión sobre la historia. En el texto Algunas reflexiones sobre los origenes del hitlerismo (1939), la pensadora procede a una evaluación analógica y a una dislocación temporal de los fenómenos históricos que le permiten subrayar las afinidades entre imperio romano y hitlerismo, con el fin de demostrar la vigencia, a lo largo de los siglos, del dominio de la fuerza a través de un modelo de ejercicio del poder, fundamentado en la violencia, que es valorado por parte de la contemporaneidad como un ejemplo de grandeza. La historia es reactivada en el presente para poder hablar de forma nueva a "la posteridad, que jamás escucha a los vencidos" ${ }^{\text {46. }}$

La analogía entre el sistema hitleriano y la Roma antigua es tan sorprendente que se podría creer que desde hace dos mil años sólo Hitler ha sabido imitar correctamente a los romanos. Si no es inmediatamente evidente a nuestros ojos es porque casi hemos aprendido a leer en Corneille y en el De viris; estamos acostumbrados a ponernos en lugar de los romanos, aunque fuera la Galia de lo que se apoderaron; hoy, cuando nos encontramos en una situación análoga, pero en la que es nuestro enemigo el que representa el papel de Roma, no reconocemos la analogía. Pues, son las conquistas que amenazan las que horrorizan; desde el punto de vista del conquistador siempre son buenas y hermosas. Además, no conocemos la historia romana más que por los propios romanos y por sus súbditos griegos, obligados, los desdichados, a adular a sus amos; así, hay que hacer un esfuerzo de crítica continua para valorar justamente la política de Roma. No poseemos la versión que habrían podido dar de ella los cartagineses, los españoles, los galos, los germanos o los bretones ${ }^{47}$.

$\mathrm{Si}$, por una parte, los horrores contemporáneos son para Weil explicables como herencia de una tradición política que ha institucionalizado y afinado el uso de la violencia política, por otra, su argumentación tiene más bien el fin de criticar una ambigüedad moral que consiente su uso cuando ésta no afecta directamente a la comunidad que pronuncia el "nosotros". La creación de márgenes de invisibilidad política y ética dentro de los cuales las víctimas ya no son consideradas como tales y la violencia está permitida, mientras que el poder es idolatrado, son el verdadero objetivo polémico de Weil. Bajo esta perspectiva, se puede entender cómo la historia y el lenguaje se convierten en los campos de batalla en los que se dirime la lucha por la decibilidad y por el sentido: los oprimidos se tienen que vincular a la historia de

\footnotetext{
44 Cfr. Weil (1996).

45 Cfr. Gabellieri (1985), p. 271.

46 Weil (2007), p. 239.

47 Ibíd., pp. 237-238.
} 
los vencidos para conseguir una emancipación real, para descentrarse del punto de vista de los dominadores y rediseñar un patrimonio cultural propio, para invertir la escala de valores y conseguir una independencia ante todo simbólica ${ }^{48}$ :

Se habla de castigar a Hitler. Pero a Hitler no se le puede castigar. Hitler deseaba una sola cosa y la tiene: entrar en la historia. Aunque se le mate, se le torture, se le encarcele o se le humille, la historia estará siempre ahí para proteger su alma de que la alcance el sufrimiento y la muerte. Lo que se inflija será inevitablemente muerte histórica, sufrimiento histórico: historia [...] Sea lo que sea lo que se le haga a Hitler, nada le impedirá considerarse un ser grandioso. Y, sobre todo, nada impedirá que, dentro de veinte, cincuenta, cien o doscientos años un muchachito soñador y solitario, alemán o no, piense que Hitler fue alguien grandioso, que tuvo de punta a cabo un destino grandioso, y desee con todas sus fuerzas alcanzar un destino parecido. Desgraciados sus contemporáneos si ocurre tal cosa. El único castigo que se puede infligir a Hitler y que puede alejar de su ejemplo a los muchachos sedientos de grandeza de los siglos futuros es una transformación tan completa del sentido de lo que es grande que excluya por completo a Hitler ${ }^{49}$.

La estrategia que Weil plantea para obtener este resultado es, una y otra vez, histórica: la construcción de un presente que no perpetúe la lógica del pasado pasa por atender a una historia que proporcione una diferente configuración simbólica: un distinto orden de grandeza. Una lectura del pasado que rechace sin ambivalencias la idolatría de la fuerza y, con ella, de la violencia es, al mismo tiempo, una mirada atenta a la sabiduría transmitida por las civilizaciones desaparecidas que han dejado huellas frágiles, pero todavía legibles ${ }^{50}$. El pasado asume en este modo, bajo la forma de memoria, el valor de categoría política dado que la "pérdida del pasado, individual o colectivo, es la gran tragedia humana"s1.

Sería vano apartarse del pasado y no pensar más que en el futuro. Es una ilusión peligrosa incluso creer que hay en ello una posibilidad. La oposición entre pasado y futuro es absurda. El futuro no nos aporta nada, no nos da nada; somos nosotros quienes, para construirlo, hemos de dárselo todo, darle nuestra propia vida. Ahora bien: para dar es necesario poseer, y nosotros no tenemos otra vida, otra savia, que los tesoros heredados del pasado y digeridos, asimilados, recreados por nosotros mismos. De todas las necesidades del alma humana, ninguna más vital que el pasado ${ }^{52}$.

Es preciso destacar que, para Weil, la asunción del pasado como categoría política no tiene un carácter reaccionario, sino que es la consecuencia teórica de la crítica a la ideología del progreso, la cual, desplazando al futuro la mejora de las condiciones actuales, mantiene y perpetúa la misma lógica que pretende subvertir. Lo que Weil repudia, coherentemente con su reflexión anterior, es el juego de espejos puesto en marcha por el poder político para seguir aplastando a los hombres y, frente a ello, desencadena el potencial utópico del pasado. De este modo, atreverse a una búsqueda en la fragilidad de la memoria, en la compasión para las víctimas -para

48 Cfr. Tommasi (1995), pp. 51-72.

49 Weil (1996), p.177.

50 Cfr. Forni Rosa (2009), p. 28.

51 Weil (1996), p. 103.

52 Ibíd., pp. 56-57. 
todos aquellos que han padecido la fuerza-, se convierte en un ejercicio político, un adiestramiento del pensamiento para que sea receptivo a otro tipo de estímulos, para plantear una sociedad que se nutra de diferentes valores: de justicia y no de fuerza, de caridad y no de dominio, de verdad y no de ilusiones:

el pasado es real en los espejos que reflejan la vulnerabilidad de la memoria y lo poco que los documentos pueden ayudar a reforzarla; su recuperación pasa por la piedad que permite aferrarse a las huellas escasas y dispersas de quienes tuvieron una experiencia real, de quienes sufrieron la ley de la fuerza, su incorporación al presente, por la atención a través de la que la verdad que encierran desciende ${ }^{53}$.

Para proceder en este recorrido lo que hace falta, según Weil, es un método de investigación histórica que preste atención a lo que los documentos ocultan, a la fragilidad de una memoria que no ostenta el poder de la fuerza porque, advierte Weil: "es absolutamente falso que un mecanismo providencial transmita lo mejor de cada época a la memoria de la posteridad. Por la naturaleza de las cosas, lo que se transmite es la falsa grandeza" ${ }^{44}$ :

La historia se basa en documentos. Un historiador se veda profesionalmente a sí mismo las hipótesis no basadas en nada. Esto es, aparentemente, muy razonable, aunque en realidad muy deficiente. Pues como la documentación tiene lagunas, el equilibrio del pensamiento exige tener presentes hipótesis sin fundamento, a condición de que ello se haga explicitando que carecen de fundamento y siempre que haya varias hipótesis respecto de cada cuestión. Con mayor razón, es necesario leer los documentos entre líneas, trasladarse uno enteramente, con olvido total de sí mismo, a los acontecimientos evocados, dedicar atención durante mucho tiempo a los pequeños detalles significativos, y discernir en ellos todo su significado. Pero el respeto por el documento y el espíritu profesional del historiador no disponen a la reflexión para este tipo de ejercicio. El llamado espíritu histórico no llega a atravesar el papel para encontrar la carne y la sangre; ese espíritu consiste en la subordinación de la reflexión al documento. Pero por la naturaleza misma de las cosas los documentos proceden de los poderosos, de los vencedores. La historia no es más que una compilación de las declaraciones de los asesinos acerca de sus víctimas y sobre sí mismos ${ }^{55}$.

Lo que Weil propone es una lectura del pasado consciente de la distinción entre éste y su envoltura en la narración histórica. Según apunta Carmen Revilla: "la mirada al pasado hace visible no sólo su presencia actual, sino también que la historia es un ámbito de poder, gestionado, en consecuencia, como el de la política con el que mantiene una correspondencia y estrecho parentesco, siguiendo sus criterios, principios y normas" ${ }^{\text {" }}$. A la vez, es este mismo significado político lo que hay que invertir: si es cierto que la búsqueda de Simone Weil en las tradiciones y las doctrinas cuya inspiración procede de una fuente, a su modo de ver, no contaminada por la idolatría de la fuerza, no nace en ella de una inquietud puramente historiográfica,

\footnotetext{
Revilla (2003), p. 66.

Weil (1996), p. 181.

Ibíd., pp. 175-176.

Revilla (2003), p. 66.
} 
sino que es una de las dimensiones de su interés religioso - con la que nutre sus meditaciones espirituales- de igual manera ésta se convierte inmediatamente en una preocupación de carácter político: en el deseo de pensar y generar una transformación radical del mundo contemporáneo ${ }^{57}$ :

En la catástrofe de nuestro tiempo, verdugos y víctimas son unos y otros, ante todo, los involuntarios portadores de un testimonio sobre la miseria atroz en cuyo fondo yacemos. Para tener derecho a castigar a los culpables tendríamos primero que purificarnos de su crimen, guardado en nuestra propia alma con toda suerte de disfraces. Pero si conseguimos realizar esta operación, cuando lo hayamos logrado ya no tendremos deseo alguno de castigar, y, si nos creemos obligados a hacerlo, lo haremos lo menos posible y con extremo dolor ${ }^{58}$.

Como reconoce Wanda Tommasi, en la concepción del pasado de Weil, en su atención a los vencidos y a los oprimidos, se juntan dos exigencias: de una parte, eliminar la culpa de las víctimas, revelando la inconsistencia de las razones de los opresores; de otra, asumir la responsabilidad política de los crímenes cometidos tanto por nuestros antepasados, como por nosotros mismos: la necesidad de compartir la culpa, asumiendo la responsabilidad ética y política de la perpetuación de un idéntico modelo de gestión del poder. Esta obligación implica que el recurso a la violencia, aún cuando sea inevitable, no se pueda justificar de forma trascendente: es una responsabilidad que los hombres tienen que aceptar entera en todas sus penosas consecuencias $^{59}$. La condena de Roma y, con ella, de Israel, aunque resultado de un conocimiento escaso de las fuentes y orientada en parte por prejuicios, tiene el significado político de un dispositivo de crítica a la fundamentación teológicopolítica del poder: Dios está ausente del mundo y cualquier reclamación en torno a su intervención no puede sino ser el resultado de una voluntad de legitimación del uso y abuso de la violencia y la fuerza. Sin embargo, la posición weiliana frente a la tradición hebraica sigue siendo un campo abierto para la crítica, dentro del cual la meditación constante sobre la desdicha constituye un vector capaz de instaurar un diálogo profundo con las aporías vigentes en el pensamiento contemporáneo y de rescatar la exigencia de una reflexión en torno a una primera dimensión -prepolítica- de la justicia. Se ha visto cómo esta concepción tiene afinidades con la reclamación, en los últimos años, de una justicia anamnética.

\section{Conclusiones}

Weil murió en 1943 y, como Benjamin, no llegó a ver la realidad surgida tras la Segunda Guerra Mundial y probablemente no conoció muchos de los horrores y de los crímenes que forman parte de nuestro imaginario político. No obstante, su concepción del pasado -como campo de batalla en el que se enfrentan historia y memoria- la lleva a una definición de justicia que se coloca en los extremos de una idea de fuerza entendida como legitimación política de la violencia. Según

\footnotetext{
Cfr. Bea (1992), p. 157.

Weil (1996), p. 187.

Cfr. Tommasi (1983), p. 151.
} 
un rasgo característico de su filosofía, Weil desarticula las nociones que emplea a través de una reflexión que se emplaza en distintos niveles: social, político, místico, cultural. De este modo, la justicia se convierte en la esencia misma del orden del mundo, en una realidad presente en el corazón de los hombres y en una práctica a la que la historia proporciona aprendizaje ${ }^{60}$. Weil, como Benjamin, desestructura el vínculo entre política y violencia, reconociendo a esta última como la condición lógica e histórica del derecho. La totalidad de la historia -desde Roma hasta al Estado moderno y al totalitarismo- puede entonces ser interpretada como la historia de la dialéctica entre derecho y violencia, según un movimiento que subordina el primero a la segunda. De esta forma, la justicia se halla, para Weil, en el espacio místico -teológico para Benjamin-que se encuentra fuera de la historia y que puede penetrar en ella a través de un proceso de discernimiento y rechazo de la fuerza que haga manifiesto el gesto de atención para los oprimidos -la compasión para las víctimas- como principio operante dentro de la realidad social. Sólo inspirándose en un pasado que ha reconocido la existencia de la fuerza y la realidad de la justicia se puede pensar en instaurar un orden político más ecuánime y en rendir la verdadera compensación a todos los que han padecido injusticia a lo largo de los siglos. Las civilizaciones a las que hay que mirar son para Weil la griega, la egipcia, la antigua civilización egeo-cretense, la occitana: cada una de ellas ha recibido una vocación -una revelación- en torno a un aspecto de la verdad sobrenatural que, a su modo de ver, sustenta la tradición de los vencidos. En particular, la civilización griega ha sabido concebir la miseria humana, la ausencia de Dios, la distancia infinita entre Dios y el hombre. La esencia de esta sabiduría está constituida por el conocimiento de la fuerza:

conocer la fuerza, significa, aun reconociéndola como casi absolutamente soberana en este mundo, rechazarla con hastío y desprecio. Este desprecio es la otra cara de la compasión para todo aquello que está expuesto a las heridas de la fuerza. Este rechazo de la fuerza encuentra su plenitud en la concepción del amor ${ }^{61}$.

El conocimiento de la fuerza como soberana en el mundo es un conocimiento esencial y preliminar para reconocer la realidad de la justicia que es "soberanía de la soberanía"62, límite exterior de la fuerza:

Acá abajo no es soberana la fuerza bruta. Por naturaleza esa fuerza es ciega e indeterminada. Lo que aquí abajo es soberano es la determinación, el límite. La eterna Sabiduría encierra este universo en una red, en una malla de determinaciones. El universo no se debate en ella. La fuerza bruta de la materia, que nos produce la impresión de ser ella misma soberanía, no es otra cosa, en realidad, que obediencia perfecta. Ahí está la garantía concedida al hombre, el arca de la alianza, el pacto, la promesa visible y palpable aquí abajo, el apoyo seguro de la esperanza ${ }^{63}$.

60 La concepción weiliana de la justicia, como muchas otras nociones presentes en el pensamiento de la filósofa, no es una idea simple; su significación se desplaza en distintos niveles: del orden natural al sobrenatural, del religioso al político. Aquí intentaremos, por la economía del escrito, dar solamente una idea de los diferentes aspectos, subrayando el matiz político. Para un tratamiento más detenido de la cuestión, véase: Tarantino (2009); Bell (1998); Rabi (1977); Greco (2006).

${ }_{61}$ Weil (1999), p. 676. La traducción es mía.

62 Ibíd., p. 219.

63 Weil (1996), p. 218. 
Para que la justicia pueda tener una realidad en el mundo hay que saber que "todo lo que se halla sometido al contacto de la fuerza se envilece, sea cual sea ese contacto. Golpear o ser golpeado es una y la misma mancha. El frío del acero es igualmente mortal en la empuñadura y en la punta" ${ }^{64}$. La concepción weiliana de la justicia cuestiona el pensamiento jurídico moderno centrado en la identificación entre justicia y derecho y, al mismo tiempo, busca los fundamentos de una legitimación nueva de las instituciones políticas. A esta tarea de replanteamiento filosófico de las bases de una sociedad no esclava de la fuerza Weil dedicará sus últimos escritos, elaborados a partir de un pensamiento que contempla ante todo la fragilidad -la vulnerabilidad- de lo humano. La enseñanza moral en la que se basa su discurso se puede resumir con las palabras que ella misma utiliza comentando la Ilíada: "no creer nada al abrigo de la suerte, no admirar nunca la fuerza, no odiar a los enemigos y no despreciar a los desdichados" 65 .

\section{Referencias bibliográficas}

Ares, B. (2011): "Entrevista a Reyes Mate, filósofo de la memoria", Revista Forma, 4, pp. 35-41.

Azzalini, M. (1999): “La causalità morale del lavoro e l'irrazionalità della storia”, en: Weil, Simone, Primi scritti filosofici, Genova, Marietti, pp. 9-106.

Bea, E. (1992): Simone Weil. La memoria de los oprimidos, Madrid, Ediciones Encuentro.

Bea, E. (2009): "La giustizia in atto. Una riflessione sull'amore in Simone Weil", en S.

Tarantino (ed.): Pensiero e giustizia in Simone Weil, Roma, Aracne, pp. 75-90.

Bell, R. H. (1998): Simone Weil. The Way of Justice as Compassion, Lanham, Rowman \& Littlefield Publishers.

Benjamin, W. (2008): Tesis sobre la historia y otros fragmentos, Ciudad de México, Universidad Autónoma.

Benjamin, W. (2010): Crítica de la violencia, Madrid, Editorial Biblioteca Nueva.

Butler, J. (2006): Vida precaria. El poder del duelo y la violencia, Buenos Aires, Paidós.

Canciani, D. (2009): "L'utopia estrema di Simone Weil. Dallo sradicamento operaio al radicamento", en S. Tarantino (ed.), Pensiero e giustizia in Simone Weil, Roma, Aracne, pp. 43-60.

Carillo, G. (2009): "In sleep a king. Sul potere che finisce”, en S. Tarantino (ed.), Pensiero e giustizia in Simone Weil, Roma, Aracne, pp. 91-109.

Cavarero, A. (2007a): "Per una storia della distruzione", Filosofia Politica, 1, pp. 13-20.

Cavarero, A. (2007b): Orrorismo, ovvero della violenza sull'inerme, Milano, Feltrinelli.

Cerutti, M. (2003): "La memoria de las víctimas. Testimonios para una reflexión ética", en J. M. Mardones/ R. Mate, La ética ante las víctimas, Barcelona, Anthropos, pp. 243-266.

Esposito, R. (1988): Categorie dell'impolitico, Bologna, Il Mulino.

Esposito, R. (1999): El origen de la politica. ¿Hannah Arendt o Simone Weil? Paidós, Barcelona.

Feldhay Brenner, R. (2005): Resistencia ante el Holocausto. Edith Stein, Simone Weil, Ana Frank y Etty Hillesum, Madrid, Narcea.

Fernández Buey, F. (2003): Poliética, Madrid, Editorial Losada.

64 Weil (1999), p. 677. La traducción es mía.

65 Weil (2007), p. 310. 
Ferry, J.-M. (2001): La ética reconstructiva, Bogotá, Siglo del hombre Editores.

Forni Rosa, G. (2009): Simone Weil. Politica e mistica, Torino, Rosemberg \& Sellier.

Forti, S. (2001): Il totalitarismo, Roma, Laterza.

Gabellieri, E. (1985): "Le sens de l'historicitè chez Simone Weil", Cahiers Simone Weil, 3, pp. $253-272$.

Galli, C. (2007): "Sulla guerra e sul nemico", en S. Forti/M. Revelli (eds.), Paranoia e politica, Torino, Bollati Boringhieri, pp. 21-42.

Giniewski, P. (1978): Simone Weil ou la haine de soi, Paris, Berg International.

González Calleya, E. (2012): Los totalitarismos, Madrid, Editorial Síntesis.

Greco, T. (2006): La bilancia e la croce: diritto e giustizia in Simone Weil, Torino, Giappichelli.

Guaraldo, O. (2009): “Comunità della perdita”, Filosofia Politica,1, pp. 73-110.

Margalit, A. (2002) Ética del recuerdo, Barcelona, Herder.

Lévinas, E. (1952): "Simone Weil contre la bible", Evidences, 4, pp. 9-12.

Mardones, J. M./Mate, R. (2003): “Introducción”, en Id. (eds.), La ética ante las víctimas, Barcelona, Anthropos, pp. 7-10.

Mate, R. (2003): “En torno a una justicia anamnética”, en J. M. Mardones/ R. Mate, La ética ante las víctimas, Barcelona, Anthropos, pp. 100-125.

Mate, R. (2011): “Justicia: autores y temas para una nueva aproximación”, en J.A. Zamora/ R. Mate (2011): Justicia y memoria. Hacia una teoría de la justicia anamnética, Barcelona, Anthropos, pp. 5-8.

Mate, R. (2011): “Memoria y justicia en Walter Benjamin”, en J.A. Zamora/ R. Mate (eds.), Justicia y memoria. Hacia una teoría de la justicia anamnética, Barcelona, Anthropos, pp. 29-39.

Maura Zorita, E. (2010): “Introducción”, en W. Benjamin, Crítica de la violencia, Madrid, Editorial Biblioteca Nueva, pp. 5-20.

Nevin, T. (1991): Simone Weil: portrait of a self-exiled Jew, London, University of North Carolina Press.

Rabi, W. (1977): “La justice selon Simone Weil”, Esprit,12, pp. 118-127.

Revilla, C. (1995): Simone Weil: descifrar el silencio del mundo, Madrid, Trotta.

Revilla, C. (2003): "La fidelidad al presente", en: Id. Simone Weil: nombrar la experiencia, Madrid, Trotta, pp. 35-56.

Ricoeur, P. (1998): La lectura del tiempo pasado: memoria y olvido, Madrid, Arrecife.

Tommasi, W. (1983): Simone Weil: Segni, Idoli e Simboli, Milano, FrancoAngeli.

Tommasi, W. (2003): "Más allá de la ley. Derecho y justicia en la última Weil”, en C. Revilla, Simone Weil: descifrar el silencio del mundo, Madrid, Trotta, pp. 51-71.

Valladolid Bueno, T. (2011): "La justicia reconstructiva: presentación de un nuevo paradigma", en J.A. Zamora/ R. Mate (eds.): Justicia y memoria. Hacia una teoría de la justicia anamnética, Barcelona, Anthropos, pp. 217-248.

Weil, S. (2011): En casa de los Weil. André y Simone, Madrid, Trotta.

Weil, S. (1995): Reflexiones sobre las causas de la libertad y de la opresión social, Barcelona, Paidós.

Weil, S. (1996): Echar raices, Madrid, Trotta.

Weil, S. (1999): “En quoi consiste l'inspiration occitaine?”, en Id., Oeuvres, Paris, Gallimard, pp. 671-680.

Weil, S. (2007): Escritos históricos y políticos, Madrid, Trotta. 